\title{
Uma crítica ao reducionismo filosófico da Química à Mecânica Quântica como elemento fundamental para a formação de professor
}

\author{
A critique of philosophical reductionism in Chemistry regarding \\ Quantum Mechanics as a fundamental element for teacher education
}

Daniel Augusto Barra de Oliveira

iD Verenna Barbosa Gomes

Universidade Federal do Norte do Tocantins (UFNT), Araguaína, TO, Brasil.

Autor Correspondente: danielchem@uft.edu.br

Resumo: A filosofia da ciência é uma área do conhecimento muito importante para o Ensino de Química. Ela pode projetar uma nova luz sobre os conceitos usados em sala de aula, ao mesmo tempo em que leva o professor a inquirir a epistemologia da ciência. Nesse artigo, mostramos como a questão filosófica do reducionismo pode ser abordada no Ensino de Química. O reducionismo pode ser discutido em sala de aula por professores e alunos, com base nos pressupostos argumentativos aqui apresentados, sendo imprescindível que essa disciplina seja trazida para os currículos da licenciatura em Química.

Palavras-chave: Reducionismo; Ensino de química; Filosofia da ciência; Mecânica quântica.

Abstract: Philosophy of science is a particularly important field of knowledge for chemistry teaching. It can shed a new light on the concepts used in the classroom, at the same time as it may lead the teacher to investigate the epistemology of science. In this paper, we demonstrate how the philosophical question of reductionism can be addressed in Chemistry teaching. Reductionism should be discussed in the classroom by teachers and students, based on the argumentative assumptions shown in this study, and it is essential that this topic be brought to the Chemistry Degree curricula..

Keywords: Reductionism; Chemistry teaching; Philosophy of science; Quantum mechanics. 


\section{Introdução}

O termo redução é usado de várias maneiras na ciência e na filosofia. Múltiplas teorias podem ser reduzidas a uma simples teoria, se uma mais simples explica tudo que as outras explicam. Por exemplo, antes das leis de Newton, havia muitas teorias não relacionadas que pareciam explicar fenômenos particulares. Todas, entretanto, foram reduzidas, com o sucesso das três leis que explicam o movimento dos corpos. No entanto, há outro tipo de redução que é, também, importante no contexto da ciência e do seu caráter investigativo. Assim que uma teoria nomeia ou rotula um objeto como membro de alguma categoria ou grupo, essa outra forma de redução ocorre. Quando nomeamos um objeto como a maçã, por exemplo, há um conjunto de propriedades que são compartilhadas com outros objetos que designam esse tipo de fruto. No entanto, cada maçã é diferente das outras maçãs de muitas maneiras e, portanto, quando reduzimos nossa concepção do objeto para a maçã, estamos ignorando todas aquelas outras propriedades. Portanto, a redução, nesse sentido, ignora ou oculta muito do que é único sobre um determinado objeto, e esse é um movimento prático que, natural e habitualmente, fazemos nas esferas que vão desde o nosso dia a dia, até a tecnologia e a ciência (NUGENT, 2018).

Diante do exposto, a questão central sobre a qual nos debruçamos é a de que o reducionismo da ciência, em especial da química à mecânica quântica, discutida neste artigo, demanda um olhar mais criterioso acerca do estudo da natureza da química. Em virtude disso, para pensar o reducionismo no contexto do ensino da matéria, é preciso estabelecer uma relação frutífera entre o tema em questão e a formação docente em química, de modo a proporcionar aos futuros professores um entendimento mais profundo sobre a natureza dessa ciência e, possivelmente, incitá-los a pensar de forma mais crítica nos critérios de seleção dos conteúdos a serem ensinados. São discussões que, acreditamos, estabelecem um diálogo com a natureza do conhecimento químico, e podem contribuir para minimizar equívocos conceituais, principalmente no que diz respeito aos conceitos em que a explicação a nível submicroscópico da matéria é confundida com as características macroscópicas. Nessa perspectiva, diversos aspectos idiossincráticos da natureza da química podem ser mais bem compreendidos pelos futuros professores, de modo a contribuir com o conhecimento tácito desses alunos em formação.

Entretanto, frente a isso, esbarramos no entrave da ausência, ou incipiência, dessa discussão nos cursos de licenciatura em Química, minando as possibilidades de fomentar importantes debates em sala de aula acerca do conhecimento químico fundamentado na filosofia da Química. Considerando essa questão, este artigo tem como objetivo principal trazer uma abordagem das questões relativas ao reducionismo no Ensino de Química, com foco em uma mudança de perspectiva na aplicação de alguns conceitos usados na área. Como desdobramento, pretende-se fomentar essa discussão nos cursos de licenciatura em Química, locus da formação de professores que vão trabalhar diretamente os conceitos dessa ciência com os estudantes.

É importante que se tenha em mente como os pressupostos da mecânica quântica adentraram na Química como explicação formal da teoria atômica. O leitor não familiarizado com a mecânica quântica deve atentar-se a alguns fatos considerados demasiado relevantes para serem omitidos no início da discussão sobre o tema. No 
início do século $\mathrm{XX}$, os princípios clássicos da Física foram questionados com experimentos que exigiam um formalismo matemático-teórico diferente. O experimento do corpo negro foi o marco iniciador das controvérsias. Um corpo negro é um corpo que absorve todos os comprimentos de onda. A dificuldade apontada neste experimento reside em explicar a emissão de luz em altas temperaturas para um corpo dessa natureza. O arcabouço teórico vigente se direcionava para paradigmas como a catástrofe do ultravioleta, na qual as equações matemáticas correntes convergiriam para frequências de emissão extremamente pequenas. Notadamente, esse problema foi interpretado teórico-experimentalmente por Planck, que lançou mão das teorias clássicas e usou a ideia dos quanta para explicar o comprimento de onda, que se transformariam em pacotes de energia denominados quantum. Mais tarde, Einstein fez uso das explicações lançadas por Planck para explicar o experimento do efeito fotoelétrico. Nesse caso, a luz lançada em uma placa metálica é capaz de expelir elétrons. Os elétrons são ejetados da placa somente se a luz tiver a frequência adequada, ou seja, quanto mais fótons, maior injeção de elétrons. A ideia de que, quando excitados, átomos emitem comprimentos de onda específicos, já residia na história da atomística.

As explicações experimentais suscitaram um novo entendimento sobre a natureza da luz e, consequentemente, do átomo. Bohr usou os pressupostos já tratados aqui para quantizar a órbita dos átomos, criando um modelo semiquântico. Inicialmente, a explicação foi satisfatória para o espectro do átomo de hidrogênio, mas, posteriormente, mostrou-se insuficiente na abordagem de átomos mais complexos. A teoria quântica continuaria seu avanço sobre os modelos atômicos.

Modelos como o de Schröedinger fazem uso de uma equação ondulatória cuja solução gera uma função de onda, a qual não tem significado físico, apenas o seu quadrado integrável, que é a probabilidade de encontrar os elétrons em uma região do espaço. Nesse momento, os modelos deterministas clássicos pareciam estar superados. A incerteza de Heisenberg traduziria um novo paradigma no qual não se pode ter certeza da posição e momento da partícula ao mesmo tempo. Está criado o espaço para as explicações quânticas da química.

Ocorre, então, o surgimento da química quântica, que conversa parcialmente com a mecânica quântica de fato, como será discutido ao longo do texto. O advento de computadores mais robustos permitirá o florescimento da química quântica. Modernamente, pode-se explicar ligações químicas por meio da combinação linear de orbitais atômicos, e é possível predizer propriedades físico-químicas a partir de resoluções aproximadas da equação de Schröedinger, como as de Hückel, Mulliken, Hartree e Roothaan. Ainda que essas aproximações suscitem o brilho considerável que a química quântica possui, são formulações aproximativas que não entregam valores exatos. Então, poderia ser a química reduzida à mecânica quântica original, conforme as afirmações de Dirac? Ou, na verdade, temos um novo arcabouço teórico-experimental, conhecido como química quântica, que conversa parcialmente com a mecânica quântica de outrora?

Nos próximos tópicos serão discutidas algumas posições filosóficas acerca do reducionismo da química à mecânica quântica, e sua aplicabilidade no ensino da disciplina. Na primeira parte, será tratada a proposta do reducionismo da química à mecânica quântica; e na segunda, abordaremos especificamente o reducionismo da química e suas aplicações no ensino de conceitos dessa área do conhecimento. 


\section{A química e o reducionismo à mecânica quântica: onde ele é discutivelmente aplicado}

Nagel (1961) estipulou duas condições para que uma teoria possa ser reduzida à outra, a conexão e a derivação. Essas duas condições têm que ser concomitantemente preenchidas. Nagel definiu, ainda, duas vertentes de reducionismo, o homogêneo e o heterogêneo, que podem ser aplicadas a depender do tipo de teoria. No reducionismo homogêneo, uma teoria é reduzida à outra sem acréscimo de conceitos novos. Em contrapartida, no reducionismo heterogêneo, uma teoria assimilaria os conceitos de outra teoria.

A redução da química à mecânica quântica estaria fundada no reducionismo heterogêneo. Nesse sentido, a química poderia ser derivada da física, via a solução da equação de Schröedinger, e os demais conceitos poderiam ser derivados ou acrescidos. A resolução da equação de Schröedinger propicia os números quânticos que são característicos na química, para explicar a ideia de orbitais atômicos. São derivadas desses conceitos as teorias que explicam a ligação Química como a Linear Combination of Atomic Orbital (LCAO). Então, muitos dos conceitos da química são consequências de teorias derivadas da teoria quântica.

Para a perspectiva reducionista, modelos quânticos e químicos são a mesma coisa. No entanto, a estrutura da teoria química codifica tipos de reações químicas de acordo com a similaridade química de grupos característicos de átomos, os quais possuem numerosas regras gerais para descrever suas combinações. Há diferenças importantes do modelo químico para o modelo físico quântico, no qual as estruturas físicas são descritas em termos de coordenadas espaciais. Então, essas coordenadas são usadas para descrever as estruturas e suas combinações com conceitos gerais, que são quimicamente significativos. E, devido ao fato de as propriedades químicas conseguirem descrever mudanças nas substâncias, elas podem ser utilizadas como guia para a predição e criação de novas substâncias no laboratório (SCHUMMER, 2006).

No contexto químico, as moléculas são objetos não quânticos em um sentido individual e local. As moléculas têm propriedades definidas a qualquer momento, preservam sua identidade através da mudança de propriedades, e sempre possuem uma posição e uma forma definidas. Nessa perspectiva:

O alfa e o ômega da química molecular é a doutrina de que as moléculas existem como objetos individuais, e que cada molécula tem uma forma, caracterizada por sua estrutura molecular. A noção de estrutura molecular é também um conceito clássico, já que se baseia na suposição das posições e momentos inequívocos dos núcleos, suposição que contradiz a contextualidade quântica (PRIMAS, 1983, p. 216, tradução nossa).

A não localidade quântica é um conceito interessante que tem uma função operacional. Dadas partículas emaranhadas colocadas à distância, uma medição em uma das partículas muda instantaneamente o estado quântico da outra. Sempre que um par de elétrons está em um estado singleto, a versão padrão da mecânica quântica implica que o valor do $\mathrm{x}$-spin de cada elétron será igual e oposto ao valor do x-spin do outro, e da mesma forma para os valores dos y-spins de outros dois elétrons. Por outro lado, a não localidade da mecânica quântica exclui o conceito espacial de forma 
molecular (PRIMAS, 1983). Então, para conceber a molécula como um objeto individual com sua própria forma, é necessário ignorar as correlações quânticas. Por sua vez, o estado da molécula determina suas propriedades, como na física clássica.

A química molecular exclui a possibilidade de superposições no espaço de Hilbert. Por exemplo, se os isômeros químicos, com sua própria forma, correspondem a vetores de estado diferentes, então a superposição faz sentido do ponto de vista quantum-mecânico:

Qual é a forma da superposição hipotética (estado de vetores correspondentes) destas duas espécies? Existe uma razão adequada para excluir tais superposições? Que razão pode ser dada - do ponto de vista da mecânica quântica - para a sistemática química? (AMANN, 1992, p. 32, tradução nossa).

Esses e outros argumentos têm sido usados para enfatizar que a molécula estudada pelo químico molecular é um indivíduo local, "[...] que existe separada e independentemente a sensação de que pode consistentemente dizer 'ter' certas propriedades, quer interaja ou não com qualquer outra coisa" (WOOLLEY, 1978, p. 1074). Nessa ontologia clássica, a forma da molécula depende da disposição espacial de seus átomos locais e individuais, cujas localizações são dadas pelas posições definidas dos núcleos clássicos. Embora os elétrons sigam órbitas indefinidas, eles também são indivíduos localizados em uma região do espaço próximo aos núcleos, com uma distribuição probabilística dada pela função de onda total. Em outras palavras, a molécula é constituída por núcleos clássicos e elétrons semiclássicos, isto é, indivíduos cujo comportamento não é governado por equações clássicas de movimento, mas por uma equação que determina sua posição apenas de maneira estatística. Esse quadro é completamente alheio à mecânica quântica, em que se pode falar estritamente apenas do sistema de moléculas, descrito por todo o seu vetor de estado não separável, mantendo correlações com outros sistemas quânticos, e cujos componentes não são indivíduos clássicos, mas subsistemas quânticos com as mesmas características quânticas, isto é, contextualidade, e não localidade.

Temos, então, duas posições: uma, que se poderia chamar de posição teoricismo, e outra posição, chamada experimentalismo. A primeira converte o conhecimento de substâncias como meio para o entendimento dos átomos e das moléculas a serem consideradas como um fim em si, culminando no modelo reducionista físico. Nesse caso, os átomos e moléculas são reduzidos às suas posições no espaço de Hilbert, onde se vislumbra a resolução da equação da onda com consequente integração para a obtenção das propriedades de interesse, como aplicação do operador Hamiltoniano para a obtenção da energia. Já na segunda posição, o conhecimento de átomos e moléculas é apenas um meio teórico para compreender o comportamento das substâncias (BENSAUDE-VINCENT, 1999).

Um conceito que poderia subsidiar o reducionismo físico seria o conceito de camadas eletrônicas. No entanto, um olhar mais crítico acerca do assunto revela que tal associação não corresponde à realidade da atual mecânica quântica. O fato mais notável é que o conceito de orbitais eletrônicos não existe de acordo com a mecânica quântica, embora possa ser útil como dispositivo explicativo. Esse resultado está incorporado no princípio da exclusão de Pauli (1946), o qual é frequentemente esquecido em detrimento da versão inválida do princípio, que não defende a noção 
de orbitais eletrônicos (SCERRI, 1991, 1994, 1995). Essa situação tem implicações interessantes, pois os conceitos de orbitais utilizados na química não podem ser reduzidos à mecânica quântica.

Ademais, frente às notórias contribuições da conhecida química quântica ao dimensionamento de ligações químicas com resultados próximos aos dados espectroscópicos, propriedades óticas e termodinâmicas, é importante ressaltar as aproximações realizadas pelos métodos ditos ab-initio. Como base, esses métodos utilizam a aproximação de Born-Oppenheimer para simplificar os cálculos. Outras aproximações são utilizadas para contornar o problema de muitos corpos. Na aproximação de Hartree-Fock, um elétron interage com o campo médio gerado pelos demais elétrons, criando os problemas pertinentes à energia de correlação. Esse efeito é suprido pelos métodos descritos pós Hartree-Fock. As aproximações envolvem, ainda, a expansão das funções de onda como séries infinitas. O problema é que os métodos fazem uma estimativa superior da energia, enquanto o cálculo da energia inferior é um problema aberto em química quântica (WEINHOLD, 1972), sugerindo uma descrição que não é completamente realística do sistema molecular.

Alguns autores, como Mario Bunge afirmam que o conceito de composição química não pode ser reduzido pela física. À primeira vista, a química é incluída na física porque o sistema químico parece constituir uma espécie particular de química física. Mas, essa expressão é um equívoco, pois o que é físico em um sistema químico são os componentes, e não o próprio sistema, que possui propriedades emergentes, além das propriedades físicas (BUNGE, 1982). Um exemplo dado pelo autor é o das propriedades de uma composição que muda com o tempo. Os dados relativos às posições de átomos e moléculas não revelam essas mudanças. Podem ser calculadas certas propriedades, mas não é possível apontar algo na matemática que possa ser identificado como uma ligação química. Esse conceito é perdido no modelo reducionista (PRIMAS, 1983).

A mecânica quântica é construída sobre axiomas, teorias e leis. Para o caso da química, existem dois problemas: o primeiro reside no fato de que a área não possui, notoriamente, leis como aquelas provenientes dos postulados newtonianos ou outras leis da física. O segundo é que sua noção de axiomas parece não ser tão clara, dada a falta de rigor matemático na química em geral (SCERRI, 1997), embora se tenha buscado tal formalismo em alguns casos (SCHINAIDER; KRAUSE, 2014). Todavia, pode-se argumentar que a química tenha leis, como as periódicas, que permitem a construção de uma tabela. Entretanto, essas leis diferem daquelas da física, pois a recorrência de elementos se dá após certos intervalos e é somente aproximativa (SCERRI, 2000).

Os defensores do reducionismo alegam que questões referentes à descrição dos sistemas moleculares e atômicos, com suas propriedades macroscópicas correlatas, são questões de aproximação e custo computacional, podendo ser a tabela periódica reduzida à mecânica quântica (SCHWARZ, 2007). Há, também, argumentos que se concentram na ontologia da química, os quais são embasados no fisicalismo ontológico defendido por Hellman e Thompson (1975), para os quais todo objeto no espaçotempo é físico. Finalmente, sem especificar as formas de leis a serem buscadas pelas ciências de ordem superior, os princípios do fisicalismo aqui esboçados desempenham um papel regulador. Eles fazem isso incorporando certos padrões de adequação (exaustividade da ontologia e determinação da verdade e referência), pelos quais as alegações de uma física como um nível abrangente e fundamental da teoria científica 
podem ser avaliadas. Esses princípios constituem um sentido substantivo e realista para o objetivo da unidade da ciência (HELLMAN; THOMPSON, 1975). Se essa tese é associada ao reducionismo, então um tipo de redução da química à física pode ser mantido, mesmo que as teorias da química não derivem diretamente da física quântica.

A despeito dos argumentos citados acima contra o reducionismo, verificase um aumento dos questionamentos acerca da vertente metafísica do fisicalismo, como a incoerência autorreferencial (GILEAD, 2015). Na química, os argumentos contra o fisicalismo se localizam no domínio da física, que não está definido. Se as entidades químicas, tais como íons e moléculas, por exemplo, forem parte da ontologia física, pode-se argumentar que não é um caso de redução da química à física, mas, simplesmente, de expansão da ontologia física para abranger a química.

Estudos independentes sobre a ontologia química com base em mereologia foram realizados por diversos autores (EARLEY, 2005; HARRÉ; LLORED, 2011; MULDER, 2010; NEEDHAM, 1996). Esses autores apelam para uma distinção ontológica geral entre entidades, as quais podem existir, e estados nos quais elas não podem existir, porém têm características daquelas que existem, contrapondo Scerri (1991, 1994, 1995).

A disciplina que unificaria a teoria quântica à química foi prontamente chamada de química quântica. A introdução do spin do elétron e do princípio de exclusão de Pauli foi usada para explicar a formação de uma ligação química. A aproximação Combinação Linear de Orbitais Atômicos (LCAO) e a teoria da valência foram usadas para descrever a ligação química. No entanto, ainda prevalecia o problema associado à solução analítica da equação de Schröedinger para muitos elétrons. Várias abordagens foram usadas para tentar contornar essa limitação. A primeira, já discutida neste manuscrito, foi a de Born Oppenheimer. É importante notar que nenhuma delas resolve a equação de Schröedinger analiticamente. A perspectiva de Hartree (1928), por exemplo, considera a interação de um elétron com o campo médio gerado pelos outros elétrons. A posteriori (JORDAN; FOCK, 1930), foi introduzido o produto antissimétrico de férmions no método Hartree. Finalmente, Roothaan (1951) adicionou a combinação linear de orbitais atômicos ao método. Devido à aproximação inicial de Hartree, a solução para a energia do sistema contém um limite que sempre será maior do que aquele obtido pela solução exata da equação de Schröedinger.

Per-Olov Löwdin (LÖWDIN, 1955) denominou a diferença entre a energia exata daquela calculada a partir da abordagem ab-initio como energia de correlação. A energia mais baixa e precisa seria encontrada superando a aproximação de BornOppenheimer e pela inclusão de correções relativísticas. Abordagens pós HartreeFock denominadas cluster acoplado usam excitações perturbativas iterativas simples, duplas e triplas (CCSD $(T)$ ), que são capazes de realizar cálculos com uma precisão de \pm $5 \mathrm{~kJ} / \mathrm{mol}$ para moléculas pequenas e médias (KÜMMEL, 2002). Ainda existe o problema com o tempo computacional, ou seja, cálculos robustos, como aqueles derivados dos métodos de perturbação MP2 e MP3, e abordagens que usam excitações duplas e triplas são computacionalmente inviáveis para o tratamento de biomoléculas.

Para o estudo de grandes moléculas biológicas são empregados os clássicos campos de força e a mecânica quântica é substituída pela mecânica clássica. Os elétrons são esquecidos e as ligações químicas são tratadas como sistemas de massa e 
mola. As interações são descritas por equações eletrostáticas e do tipo Van der Waals. Este método é conhecido como mecânica molecular (LEACH, 2001) e essa abordagem permite o estudo da otimização e dinâmica de proteínas e outras moléculas biológicas.

Um esforço para validar os campos de força tem sido feito nos últimos anos e avaliações sistemáticas baseadas na mecânica quântica têm sido realizadas a fim de padronizar os campos de força molecular (VAN DER SPOEL, 2021). A complexidade resultante dos problemas de química quântica é facilitada pelo uso de computadores, que trazem o elemento prático dessa área do conhecimento para o ensino (ARROIO et al., 2005).

É importante salientar que a física também possui outras correlações fundamentais com a química, além da quântica. A área de termodinâmica é a aplicação dos conceitos de termodinâmica às reações químicas. A partir dos conceitos de entropia e energia livre, é possível predizer se uma reação química será ou não espontânea. A eletroquímica, por sua vez, combina conceitos termodinâmicos com aqueles de transferência e transporte de cargas para predizer a diferença de potencial do sistema.

Há, ainda, outras aplicações da física na química. Contudo, neste trabalho, restringimos as discussões sobre como a quântica é usada como pressuposto reducionista da química à física.

Esses conceitos também podem e devem ser trazidos para a discussão na sala de aula, como proposto no tópico a seguir.

\section{O reducionismo no Ensino de Química}

Qual a relação entre o reducionismo e o Ensino de Química? Pode o reducionismo trazer implicações para a área? Dialogando com Kaya e Erduran (2011), defendemos que essa perspectiva traz mais do que uma relação ontológica de dependência da química com a física. Ela também exclui possibilidades de o aluno ter uma melhor compreensão dos conceitos da química, e contribui para um déficit significativo, que dificulta o ensino e a aprendizagem da natureza do conhecimento químico. A nosso ver, essas ideias são passíveis de questionamentos e devem permear os currículos de formação de professores em química.

Outro impacto no Ensino de Química apontado na literatura (BARRETO, 2019) diz respeito à predominância de uma demasiada ênfase em aspectos quantitativos em detrimento de aspectos qualitativos, relacionais e classificatórios, que são fundamentais para a apropriação do conhecimento químico.

Frente a essas questões, aventamos a necessidade de estreitar a relação entre a química e a filosofia da química. Essa relação é um tanto rica, e com um nível de complexidade que envolve aspectos relativos ao currículo da licenciatura em química e à didática da química. Trazer para a sala de aula discussões relativas ao reducionismo não se limita apenas ao conteúdo curricular, mas também diz respeito à necessidade de ser consistente com nosso conhecimento atual de aprendizagem da ciência e de estratégias pedagógicas eficazes no ensino das ciências (ERDURAN, 2001).

Em primeiro lugar, múltiplas interpretações da relação entre estrutura molecular e composição química podem ser promovidas na discussão em sala de aula. Para esse fim, algumas tarefas interessantes podem ser projetadas para o estudo da natureza controversa da redução como tema da filosofia da química. Uma dessas 
tarefas poderia envolver a avaliação de argumentos desencadeados nas discussões com os estudantes para a relação entre estrutura molecular e composição química. A promoção da argumentação científica na sala de aula tem sido uma preocupação importante para os educadores de ciências nos últimos anos (ERDURAN, 2001). Acreditamos que estabelecer condições em que os alunos argumentem sobre determinado tema possibilita desenvolver o pensamento crítico e reflexivo desses sujeitos. Nessa perspectiva, o desenho de algumas tarefas que discutam o tema do reducionismo, ao contribuir para a promoção da argumentação no ensino de ciências, amplia o entendimento, a reflexão e o posicionamento crítico acerca da complexidade do conhecimento químico.

Nesse sentido, a inclusão do tema da redução no Ensino de Química poderia ser contemplada para promover não só o que a ciência explica, mas também como se chegou ao conhecimento em questão. Dessa forma, a complexidade da redução possibilita que estratégias pedagógicas que visem alcançar um autêntico discurso científico em sala de aula sejam pensadas e implementadas.

Uma forma importante de explicação que permeia todas as áreas da química, desde o ensino de pesquisa de fronteira, está na conversa sobre as camadas eletrônicas ou orbitais. A formação de ligações, comportamento ácido-base, química redox, fotoquímica e estudos de reatividade são regularmente discutidos por referência ao intercâmbio de elétrons entre vários tipos de orbitais (SCERRI; MCINTYRE, 1997). A análise da explicação dessa maneira pode, à primeira vista, parecer uma fala em favor da redução epistemológica da química à física, já que se acredita no discurso que as camadas eletrônicas pertencem ao nível da física atômica.

Contudo, um exame mais crítico das questões envolvidas não revela tal sustentação na física fundamental. O problema é que a explicação usada pela química para a ideia de orbitais eletrônicos não é aquela mesma proposta pela mecânica quântica. No nível quântico mais fundamental, a ideia de orbitais eletrônicos se torna ontologicamente redundante. Orbitais eletrônicos não podem ser observados segundo a mecânica quântica, embora permaneçam como um dispositivo explicativo muito útil. Esse resultado é encarnado na versão mais fundamental do princípio de exclusão de Pauli, que é frequentemente esquecido às custas da restrita e estritamente versão inválida do princípio, que sustenta a noção de orbitais. Tal situação demonstra que muitas explanações fenomenológicas adotadas pela química, que dependem da existência de elétrons, em particular, da noção de orbitais, são, na verdade, explicações que não podem ser reduzidas à mecânica quântica.

Nos cursos de nível superior em Química, nas aulas da disciplina de Química Geral, são priorizados, normalmente, os conteúdos de orbitais atômicos e interpretações quânticas. Uma importante reflexão, para esses cursos, é que o ensino precisa manifestar a natureza explicativa útil dos orbitais eletrônicos em explicações químicas, de maneira consistente com seu uso antirrealista na mecânica quântica. Em outras palavras, há uma distinção a ser feita sobre o status explicativo dos orbitais eletrônicos em química, e seu status ontológico na mecânica quântica. Portanto, há a necessidade de suscitar debates com os estudantes sobre o estatuto ontológico dos orbitais. Discussões reflexivas em sala de aula, com base em tais distinções, tendem a promover uma compreensão mais profunda das explicações da química entre estudantes universitários. 
Quais conhecimentos da química queremos que os alunos aprendam? Quais aspectos do conhecimento científico devem ser priorizados no aprendizado? A realidade do Ensino de Química nos denuncia que, na sala de aula, são abordados conceitos como composição, ligação e estrutura molecular, os quais são introduzidos sem um aprofundamento filosófico. Esse fato reflete-se em um currículo fragmentado, disciplinar e pautado ainda no tecnicismo, mostrando o desafio de repensá-lo em uma dimensão mais crítica. Os estudos de Ribeiro (2014) indicam que, mesmo que os pesquisadores da área de educação em química tenham caminhado para um currículo emancipatório, buscando a superação da racionalidade prática, ainda há uma busca por emancipação sem atenção à filosofia da química, de modo que:

\footnotetext{
As referências teóricas pertencem, em sua maioria, à sociologia, à pedagogia, com escassa atenção à filosofia, e às metaciências (filosofia, história e sociologia da ciência). As metaciências que estão integradas ao currículo são de natureza ainda positivista ou ligadas à história da filosofia da ciência. Correntes contemporâneas, como a modelo-teórica, estão ausentes, bem como a filosofia da química (RIBEIRO, 2014, p. 148).
}

Trazendo o tema da redução (com um viés filosófico) para a discussão em sala de aula, é provável que esse conceito reforce a compreensão não apenas do reducionismo, mas também desses importantes conceitos químicos. É necessário notar que a promoção do ensino do reducionismo não implica que a autonomia da química está comprometida. Em outras palavras, a escolha do foco na redução não é para minar a importância do conhecimento químico. Pelo contrário, a introdução do tema da redução na educação em química é percebida como um tipo de diferenciação da ciência química. A discussão, com foco nas diferentes perspectivas acerca do reducionismo, pode levar os estudantes a desenvolverem argumentos que os levem à compreensão da natureza da química e sua relação com outras áreas do conhecimento científico.

O conceito de leis periódicas é outro tema que pode ser abordado como vertente do reducionismo no ensino da disciplina. Se a química pode ser reduzida à física, as leis adjacentes da primeira poderiam ser prontamente explicadas pelas leis da segunda. O problema a ser colocado ao discente seria a existência de leis na química como aquelas da física. A classificação dos elementos químicos seria um exemplo bastante interessante. Será que as propriedades químicas dos elementos seguem estritamente a classificação periódica deles?

Ao aluno do Ensino Médio, o assunto do reducionismo poderia ser iniciado a partir da classificação e caracterização de um objeto. Ao classificar um objeto, colocamse os elementos comuns como classificatórios, enquanto os elementos particulares são desconsiderados. O ato de classificar uma maçã, como já mencionado no texto, desconsidera as particularidades de todas as maçãs. A posteriori, o assunto poderia ser trazido em um contexto científico. Como caracterizar um material levando em conta as suas particularidades? Como as propriedades comuns dos materiais podem ser usadas para traduzir avanços tecnológicos? O reducionismo é benéfico para ciência? Quando o reducionismo não funciona? Tais questionamentos suscitariam discussões frutuosas dentro da sala de aula, levando ao criticismo do discente e ao aprofundamento de teorias a partir do tema do reducionismo. 
Considerando essas questões, chamamos a atenção para a necessidade de se repensar o que e como ensinar, tanto na formação de professores, quanto no Ensino Médio, já que não podemos pensar nessas duas modalidades de ensino de forma dissociável. Entretanto, é preciso considerar que antes de essa discussão chegar à sala de aula no Ensino Médio, ela precisa ser contemplada na formação inicial dos professores, de modo que esses sujeitos, em suas práticas docentes, tenham condições de estabelecer debates com os alunos sobre a redução, a partir de um olhar interno da química. Como essa discussão é objeto de reflexão filosófica, defendemos e sugerimos que a filosofia da química seja contemplada nos currículos da licenciatura em química. O viés da filosofia da química poderá instrumentalizar o discurso em sala de aula sobre a natureza do conhecimento químico, e sobre conceitos da química que, muitas vezes, são incompreensíveis aos estudantes, ou são aprendidos de forma equivocada.

\section{Considerações finais para um novo começo}

Foi mostrado um panorama das discussões da redução da química à física, tendo como pressuposto o reducionismo. Na primeira vertente foi trabalhada a perspectiva filosófico-científica, mostrando que muito do que é afirmado como possível redução da química à física é passível de questionamentos teórico-experimentais. Na segunda etapa foram dados exemplos práticos da abordagem do estudo do reducionismo no Ensino de Química, e foi defendida a importância de discutir isso nos cursos de licenciatura da área de conhecimento em questão.

Dessa forma, foram apontadas, por meio do debate do reducionismo, situações em que a filosofia da química pode contribuir para a educação em química. A promoção da inclusão de perspectivas filosóficas no currículo de química sugere um afastamento de abordagens de determinados conceitos, alheios ao viés filosófico, e uma criticidade maior na seleção dos conteúdos a ensinar, bem como na sua apresentação.

O estudo da filosofia da química é ainda um meio de despertar no discente o interesse por conceitos tidos como resolvidos em boa parte dos livros didáticos da matéria. Questões atinentes à definição de orbitais e à própria teoria atômica são estudos passíveis de investigação via filosofia da química.

Dessa forma, este artigo, ao mostrar alguns paradoxos e tensões que permeiam o Ensino de Química, busca também orientar uma reflexão para docentes acerca da importância da filosofia da química, quando houver um debate sobre determinados conteúdos curriculares, especialmente dos cursos de licenciatura em nível superior. Considerando, ainda, que as discussões nos cursos de formação inicial de professores de química são pautadas nos estudos filosóficos de Feyerabend, Kuhn, Lakatos e Popper, filósofos que têm a física como modelo de ciência natural, este artigo também contribui para uma nova abordagem (nos campos epistemológico, ontológico e heurístico-metodológico) acerca da estrutura lógica da química. Tal contribuição ocorre mostrando, portanto, como o reducionismo, utilizado como ponto de partida para os estudos dos conceitos químicos, se não for bem discutido com os alunos, traz obstáculos conceituais em química e no seu aprendizado.

Nesse sentido, o estudo da filosofia da química pode contribuir para estimular a compreensão dos estudantes sobre as características específicas da área da química que a distinguem de outras ciências, como a física. Pode, além disso, minimizar tensões 
de um currículo fechado e alheio aos conteúdos de fronteira, que fazem a interface com a química.

De modo geral, as discussões elencadas neste artigo apontam para a importância de professores de química e pesquisadores da área de Educação em Química estreitarem relações e se dedicarem mais aos debates da filosofia da química, com o intuito de pensar os problemas relacionados ao ensino de conceitos da disciplina nos currículos dos cursos de nível superior e na formação de professores dessa área de conhecimento.

\section{Referências}

AMANN, A. Must a molecule have a shape? South African Journal of Chemistry, Centurion, v. 45, n. 2, p. 29-38, 1992. Disponível em: https://hdl.handle.net/10520/AJA03794350_268. Acesso em: 14 jun. 2021.

ARROIO, A.; HONÓRIO, K. M.; WEBER, K. C.; HOMEM-DE-MELLO, P.; SILVA, A. B. F. O ensino de química quântica e o computador na perspectiva de projetos. Química Nova, São Paulo, v. 28, n. 2, p. 360-363, 2005. DOI: https://doi.org/fmdvbx.

BARRETO, U. R. Ensino de química, modelos e autonomia intelectual. Scientia Naturalis, Rio Branco, v. 1, n. 4, p. 272-290, 2019. Disponível em: https://periodicos.ufac.br/index.php/SciNat/ article/view/2626. Acesso em: 15 set. 2020.

BENSAUDE-VINCENT, B. Atomism and positivism: a legend about French chemistry. Annals of Science, London, UK, v. 56, n. 1, p. 81-94, 1999. DOI: https://doi.org/b9d4ck.

BUNGE, M. Is chemistry a branch of physics? Zeitschrift für allgemeine Wissenschaftstheorie, Germany, v. 13, p. 209-223, 1982. DOI: https://doi.org/bpzqht.

EARLEY, J. E. Why there is no salt in the sea. Foundations of Chemistry, Dordrecht, v. 7, p. 85-102, 2005. DOI: https://doi.org/dgwp6f.

ERDURAN, S. Philosophy of chemistry: an emerging field with implications for chemistry education. In: BEVILACQUA, F.; GIANNETTO, E.; MATTHEWS, M. (org.). Science education and culture. Dordrecht: Kluwer, 2001. p. 165-177.

GILEAD, A. Self-referentiality and two arguments refuting physicalism. International Philosophical Quarterly, USA, v. 55, n. 4, p. 471-477, 2015. DOI: https://doi.org/f3gczt.

HARRÉ, R.; LLORED, J. Mereologies as the grammars of chemical discourses. Foundations of Chemistry, Dordrecht, v. 13, p. 63-76, 2011. DOI: https://doi.org/bdx3w9.

HARTREE, D. R. The wave mechanics of an atom with a non-coulomb central field. Part II. Some results and discussion. Mathematical Proceedings of the Cambridge Philosophical Society, Cambridge, v. 24, n. 1, 1928, p. 111-132. DOI: https://doi.org/c9gcdg.

HELLMAN, G.; THOMPSON, F. Physicalism: ontology, determination, and reduction. Journal of Philosophy, USA, v. 72, n. 17, p. 551-564, 1975.

JORDAN, P.; FOCK, V. Neue unbestimmtheit eigenschaften des elektromagnetischen feldes. Zeitschrift für Physik, Germany, v. 66, p. 206-209, 1930. DOI: https://doi.org/dp78kv.

KAYA, E.; ERDURAN, S. Integrating epistemological perspectives on chemistry in chemical education: the cases of concept duality, chemical language, and structural explanations. Science \& Education, Dordrecht, v. 22, n. 7, p. 1741-1755, 2011. DOl: https://doi.org/db3xzh.

KÜMMEL, H. G. A biography of the coupled cluster method. In: BISHOP, R. F.; BRANDES, T.; GERNOTH, K. A.; WALET, N. R.; XIAN, Y. (ed.). Recent progress in many-body theories: proceedings of the 11th international conference, Manchester, UK, 9-13 July 2001. [London]: World Scientific, 2002. p. 334-348. DOI: https://doi.org/dnmg69. 
LEACH, A. Molecular modelling: principles and applications. New Jersey: Pearson, 2001.

LÖWDIN, P.-O. Quantum theory of many-particle systems. III. Extension of the Hartree-Fock scheme to include degenerate systems and correlation effects. Physical Review, College Park, USA, v. 97, n. 6, p. 1509-1520, 1955. DOI: https://doi.org/dcgh3m.

MULDER, P. On the alleged non-existence of orbitals. Studies in History and Philosophy of Science Part B: Studies in History and Philosophy of Modern Physics, Oxford, UK, v. 41, n. 2, p. 178-182, 2010. DOI: https://doi.org/dz7szh.

NAGEL, E. The structure of science. New York: Harcourt, 1961.

NEEDHAM, P. Substitution: Duhem's explication of a chemical paradigm. Perspectives on Science: historical, philosophical, social, Cambridge, USA, v. 4, p. 408-433, 1996.

NUGENT, P. D. Reductionism in everyday life, technology, and science: an exploration of what is concealed and revealed in practice. Journal of Systemics, Cybernetics and Informatics, v. 16, n. 4, p. 47-51, 2018. Disponível em: http://www.iiisci.org/journal/PDV/sci/pdfs/IP056LL18.pdf. Acesso em: 10 set. 2020.

PAULI, W. Exclusion principle and quantum mechanics. Berlin: Springer, 1946.

PRIMAS, H. Chemistry, quantum mechanics and reductionism. Berlin: Springer, 1983.

RIBEIRO, M. A. P. Integração da filosofia da química no currículo de formação inicial de professores: contributos para uma filosofia no ensino. 2014. Tese (doutorado em Educação) - Instituto de Educação, Universidade de Lisboa, Lisboa, 2014. Disponível em: http://hdl.handle. net/10451/12152. Acesso em: 15 set. 2020.

ROOTHAAN, C. C. J. New developments in molecular orbital theory. Reviews of Modern Physics, New York, v. 23, n. 2, p. 69-89, 1951. DOI: https://doi.org/fh6vkx.

SCERRI, E. R. Bibliography on philosophy of chemistry. Synthese, Dordrecht, v. 111, n. 3, p. 305324, 1997. DOI: https://doi.org/dcbp7v.

SCERRI, E. R. Chemistry, spectroscopy, and the question of reduction. Journal of Chemical Education, Easton, USA, v. 68, p. 122-126, 1991. DOI: https://doi.org/bcrsjp.

SCERRI, E. R. The exclusion principle, chemistry and hidden variables. Synthese, Dordrecht, v. 102, p. 162-169, 1995. DOI: https://doi.org/bg2xzs.

SCERRI, E. R. Has chemistry been at least approximately reduced to quantum mechanics? PSA: Proceedings of the Biennial Meeting of the Philosophy of Science Association, Chicago, v. 1994, n. 1, p. 160-170, 1994. DOI: https://doi.org/g277.

SCERRI, E. R. Philosophy of chemistry: a new interdisciplinary field? Journal of Chemical Education, Easton, USA, v. 77, n. 4, p. 522-525, 2000. DOI: https://doi.org/cpnn4s.

SCERRI, E. R.; MCINTYRE, L. The case for philosophy of chemistry. Synthese, Dordrecht, v.111, p. 213-232, 1997. DOI: https://doi.org/fvv3ts.

SCHINAIDER, J.; KRAUSE, D. Indiscernibilidade e identidade em química: aspectos filosóficos e formais. Manuscrito, Campinas, v. 37, n. 1, p. 117-164, 2014. DOI: https://doi.org/g279.

SCHUMMER, J. The philosophy of chemistry: from infancy toward maturity. In: BAIRD, D.; SCERRI, E.; MACINTYRE, L. (ed.). Philosophy of chemistry: synthesis of a new discipline. Dordrecht: Springer, 2006. p. 19-39.

SCHWARZ, W. H. E. Recommended questions on the road towards a scientific explanation of the periodic system of chemical elements with the help of the concepts of quantum physics. Foundations of Chemistry, Dordrecht, v. 9, n. 2, p. 139-188, 2007. DOI: https://doi.org/ckgw66. 
VAN DER SPOEL, D. Systematic design of biomolecular force fields. Current Opinion in Structural Biology, London, UK, v. 67, p. 18-24, 2021. DOI: https://doi.org/gknbhk.

WEINHOLD, F. Upper and lower bounds to quantum mechanical properties. Advances in Quantum Chemistry, USA, v. 6, p. 299-331, 1972. DOI: https://doi.org/bngrsm.

WOOLLEY, R. G. Must a molecule have a shape? Journal of American Chemical Society, Washington, v. 100, n. 4, p. 1073-1078, 1978. DOI: https://doi.org/10.1021/ja00472a009. 